\title{
A LAGUNA DE AVEIRO (CENTRO DE PORTUGAL) NO SÉCULO XIX: UMA ABORDAGEM ATRAVÉS DA GEOMORFOLOGIA HISTÓRICA
}

\author{
CÁTIA BRAGANÇA MARTINS(1)
}

Resumo:

\begin{abstract}
Os documentos usados pela historiografia na reconstituição e reconhecimento dos lugares, como a cartografia antiga, livros de memórias e descrições, podem constituir importantes fontes para a análise da evolução geomorfológica de muitos espaços, sobretudo do litoral, onde os fenómenos geomorfológicos são relativamente rápidos. A laguna de Aveiro, dadas as suas características, corresponde a um espaço de cruzamento entre Geomorfologia e História, permitindo que fontes de carácter histórico forneçam dados fundamentais para a compreensão do seu comportamento e evolução. Assim, o objecto desta investigação é a análise da relação entre as construções antrópicas e a dinâmica litoral da laguna de Aveiro durante o século XIX - período de 1823 a 1886, onde, a partir de três exemplos de levantamentos cartográficos, formularemos uma hipótese de interpretação. Tal demonstrará a viabilidade desta opção.
\end{abstract}

Palavras-chave: Geomorfologia histórica; Laguna de Aveiro; Século XIX.

Abstract:

The Aveiro lagoon (Portugal) in the 19th century: an approach through historic geomorphology The documents used by History in the reconstitution and recognition of places, such as old cartography, memory and descriptions books, could be important bases for analysing the geomorphologic evolution of many areas, especially coastal areas, where geomorphologic phenomena are quite fast. Due to its particular characteristics, the Aveiro lagoon belongs to an area of intersections between Geomorphology and History, allowing historical sources to provide essential data for understanding its behaviour and evolution. Thus, the main purpose of this research is to analyse the relationship between man-made constructions and the coastal dynamics of the Aveiro lagoon during the 19th Century - in the period between 1823 and 1886 - where, from three cartographic examples, we shall construct a hypothesis of interpretation in order to highlight the methodological process that was used.

Key-words: Historical Geomorphology; Aveiro lagoon; 19th Century.

\section{INTRODUÇÃo}

Os métodos de trabalho da geomorfologia assentam tradicionalmente no trabalho de campo, no estudo de cartografia específica, a distintas escalas, e em diversos processos analíticos dos materiais recolhidos, advindos da Geografia, da Geologia e das restantes ciências exactas. Contudo, as fontes históricas usadas na reconstituição e reconhecimento dos lugares, como a cartografia antiga, livros de memórias e descrições, podem constituir importantes fontes para a análise da evolução geomorfológica de muitos espaços.

Se a arqueologia desde cedo contribuiu para esta análise, já que os dados inventariados a partir dos vestígios arqueológicos encontrados permitem uma reconstituição do clima, da vegetação e da hidrografia, as fontes usadas habitualmente pela História e, nomeadamente, pela Geografia histórica podem constituir ferramentas significativas para a compreensão geomorfológica do espaço e, até, da influência antrópica na sua evolução e comportamento. É neste contexto que surgem, a nível internacional, trabalhos como os de D.M. Helgren (1987), B. Collins (2005) ou J.D. Phillips (2005). A nível nacional, temos o exemplo do trabalho de A.F. Martins (1946), com a reconstrução do litoral no século XIV apoiado em fontes históricas, um verdadeiro precursor nesta temática, ou outros mais recentes, como o de C. Bateira (1998). Assim, é lícito falar de uma Geomorfologia histórica, um lugar de charneira entre ciências de onde poderão advir novos dados e interpretações.

Nesta perspectiva, o litoral, onde os fenómenos geomorfológicos são relativamente rápidos, permite, para além de uma leitura da sua evolução à escala

(1) Mestranda em História e Património, Faculdade de Letras da Universidade do Porto, Via Panorâmica, s/n, $4150-564$ Porto. E-mail: cbragancamartins@gmail.com. 
do tempo geológico, uma leitura geomorfológica à escala do tempo histórico.

\section{O OвJECTO De Estudo}

A laguna de Aveiro, como espaço num contexto histórico específico que influencia a sua evolução, apresenta-se como um caso de estudo onde as fontes de carácter histórico forneçam dados fundamentais para a compreensão do seu comportamento e dinâmica. Nesta perspectiva, escolhemos como objecto desta investigação a análise da relação entre as construções antrópicas e a dinâmica litoral da laguna de Aveiro durante parte do século XIX, mais precisamente entre 1823 a 1886, ou seja, em 43 anos. Trata-se de uma época para a qual existe vasta documentação, pois já se tinha aberto a "barra"1 de Aveiro. De notar que os portos, como portas de acesso e pontos fulcrais para a expansão do comércio internacional e nacional imposto pela mundialização da economia, constituem foco de atenção especial.

O período escolhido pode subdividir-se em duas fases distintas relacionadas com a dinâmica da laguna que passaremos a enunciar:

- 1823 a 1857 - fase de assoreamento da barra e ausência de projectos de construção ou melhoramento específicos, coincidente com o abandono da direcção das obras da barra de Luís Gomes de Carvalho, atravessando o período da Guerra Civil e de enorme flutuação entre os directores das obras;

- 1858 a 1886 - fase coincidente com a direcção de Silvério Augusto Pereira da Silva e da Regeneração, em que se efectuam projectos e estudos de reconhecimento da laguna, levando-se a cabo várias obras com o intuito de melhorar a barra e a navegabilidade na laguna.

Durante estas duas fases tiveram lugar importantes alterações antrópicas da laguna que resultam na sua modificação e imprimiram novas dinâmicas aos factores naturais, tornando-a um espaço onde as influências humanas e naturais se trocam e se interpenetram.

\section{Métodos E Fontes}

Apesar deste estudo se encontrar, ainda, numa fase inicial, intentar-se-á conjugar a perspectiva his- tórica, reconhecendo os contextos nacional e local determinantes na realização de projectos para a barra, com a perspectiva geomorfológica de evolução do espaço de análise.

De acordo com os documentos já analisados, recorrer-se-á a uma análise quantitativa de dados qualitativos. Por exemplo, a partir de documentos como os relatórios de obras efectuadas na barra ou de cartografia específica, far-se-á um levantamento de dados quantificáveis como a batimetria ou a largura dos canais da laguna. Da mesma forma, utilizar-se-á uma análise qualitativa a partir de dados quantitativos, ou seja, a partir dos registos de entradas e saídas de embarcações na barra e sua tonelagem poder-se-ão inferir condições gerais de navegabilidade.

Visto o objecto de estudo ser o espaço e a sua evolução, pensa-se que a cartografia produzida para o período entre 1823 e 1886 deverá constituir a parte documental fundamental da investigação. Através dela, será possível responder a grande parte das questões colocadas, pois as imagens cartográficas encontradas contêm variadíssimas informações sobre as transformações da barra e da laguna (alterações de corpos móveis como restingas, ilhas, bancos de areia, modificações na largura de canais, fundos, amplitude de marés...).

Dado que, normalmente, os documentos cartográficos são parte integrante de relatórios, projectos ou memórias relativas ao espaço cartografado, os documentos escritos completam o mapa ou, em muitos casos, abordam fenómenos que não tem expressão na figuração. Estes relatórios, projectos e memórias são muito ricos em informação e são de extrema utilidade na resposta a muitas das questões levantadas, abordando muitas vezes a metodologia seguida nos levantamentos cartográficos ou em medições de variadíssima ordem, para além de descreverem pormenorizadamente a situação da barra, os efeitos das construções executadas, as directrizes de construção e a tecnologia utilizada.

Apesar das potencialidades destes documentos há que ter uma posição crítica e reconhecer os aspectos que podem limitar o seu uso. Referimo-nos, por exemplo, ao contexto envolvente à sua produção, à intenção do seu produtor, às técnicas utilizadas e suas limitações, etc.. Contudo, para o período considerado, graças ao relativo rigor e qualidade atingido pela produção cartográfica, estes constituem-se como fontes fundamentais de trabalho.

\footnotetext{
1 A designação "barra", utilizada ao longo deste texto, refere-se ao canal, artificial ou natural, que estabelece a comunicação entre um corpo de água interior (a laguna) e o mar. Glossário das zonas costeiras, Revista de Gestão Costeira Integrada (JICZM - Journal of Integrated Coastal Zone Management) - http://www.aprh.pt/rgci/glossario/index.html.
} 


\section{A Laguna de Aveiro: Dados para REFLEXÃO}

\subsection{Aspectos Geográficos}

A laguna de Aveiro é o maior sistema lagunar da costa nacional. Localizada no Noroeste da costa atlântica, com latitude compreendida entre os $40^{\circ} 52^{\prime} \mathrm{N} \mathrm{e}$ os $40^{\circ} 30^{\prime} \mathrm{N}$ e longitude de $8^{\circ} 45^{\prime} \mathrm{W}$ a $8^{\circ} 35^{\prime} \mathrm{W}$, tem uma forma que se aproxima geometricamente a "(...) um triângulo isósceles onde o maior comprimento se desenvolve entre Ovar e Mira" (BETTENCOURT \& RAmos 2003: 3.4.). A sua largura máxima é de cerca de $11 \mathrm{~km}$, enquanto o comprimento atinge cerca de $45 \mathrm{~km}$ nos pontos mais extremos. No que respeita à área de ocupação, esta varia consoante o momento de maré considerado, apresentando uma área de cerca de $83 \mathrm{~km}^{2}$, na preia-mar, e $66 \mathrm{~km}^{2}$, na baixa-mar (J.M. DiAs 2009), ocupando a massa de água lagunar propriamente dita cerca de $113 \mathrm{~km}^{2}$ em preia-mar de águas vivas (Fig. 1).

No que respeita às suas características climáticas, estas são determinadas, em grande medida, pela forte influência das perturbações da frente polar, em que as frentes meteorológicas associadas marcam a diversidade dos estados de tempo verificados; pelas massas de ar predominantes e pela influência marítima. Assim, mais do que a atribuição de um tipo climático, parece sobretudo importante salientar o carácter atlântico do clima da área lagunar que influenciará a sua evolução e comportamento: amplitudes térmicas reduzidas ao longo do ano (inferiores a $10^{\circ} \mathrm{C}$ ); nevoeiros persistentes, sobretudo no Verão; ventos de orientações bem definidas, sobretudo de Norte e de Noroeste, que influenciam a direcção dos cordões de areia e sistemas dunares, bem como a quantidade de areias disponíveis para a sua construção; precipitações relativamente abundantes, mas muito variáveis interanualmente, e distribuídas de forma heterogénea ao longo do ano ${ }^{2}$. Neste âmbito há episódios de precipitações intensas que alteram a dinâmica sedimentar e as correntes no interior da laguna, uma vez que o aumento do caudal provoca inundações e arrasta uma maior quantidade de sedimentos, contribuindo
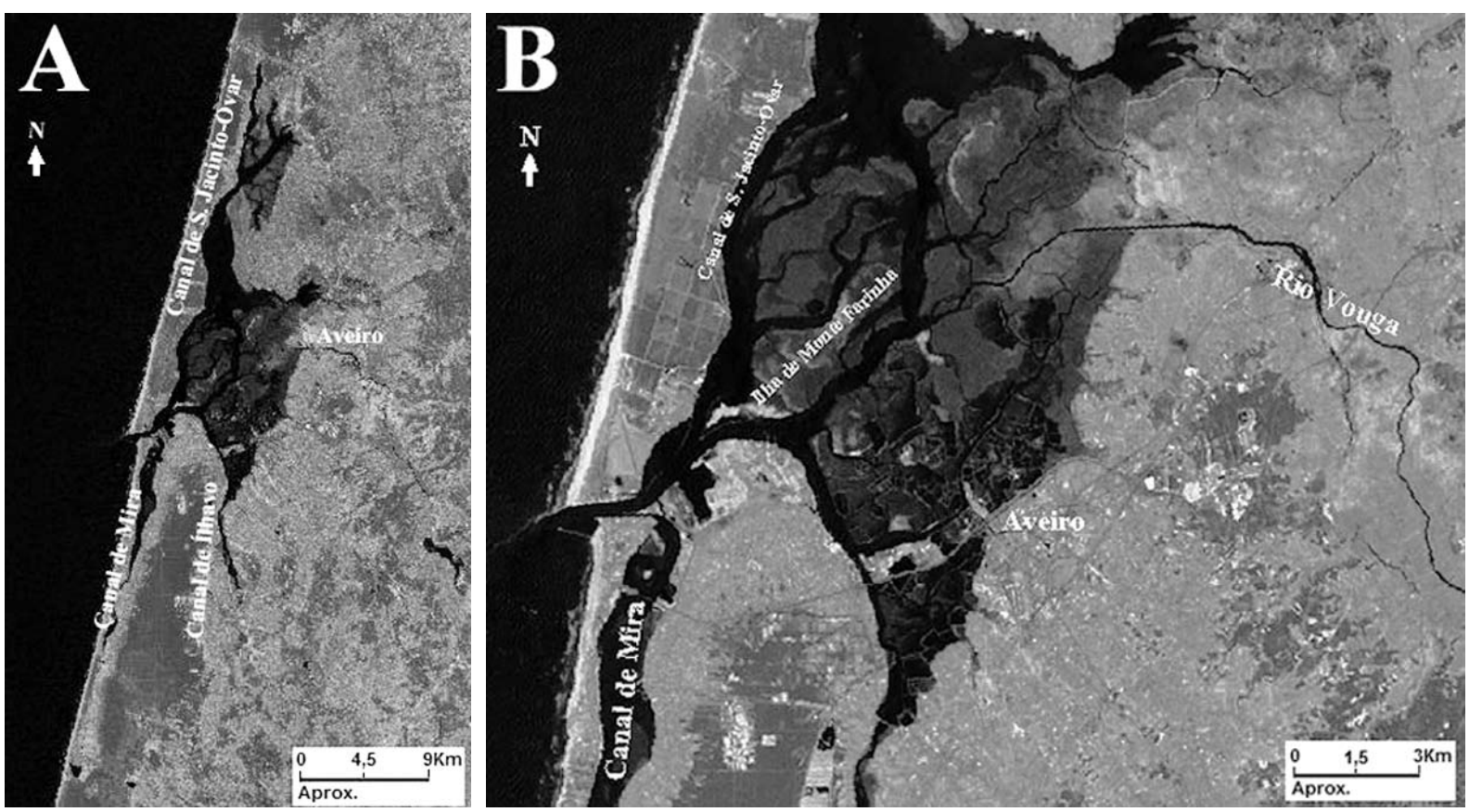

Fig. 1. A - Laguna de Aveiro - Imagem da banda 4 com expansão linear do contraste tonal; Extracto da cena 204/32 (Landsat 7 ETM+); B - Composição colorida 5-4-3 RG, ampliação da área de entrada da Laguna; Extracto da cena 204/32 (Landsat 7 ETM+) (seg. Global Land Cover Facility - http://glcf.umiacs.umd.edu/index.shtml).

Fig. 1. A - Aveiro lagoon - Picture of band 4 with linear expansion of the tonal contrast; Extract from scene 204/32 (Landsat 7 ETM+); B - coloroured composition RG 5-4-3, enlargement of the entry area of lagoon, 204 Extract from the scene/32 (Landsat 7 ETM+) (after Global Land Cover Facility - http://glcf.umiacs.umd.edu/index.shtml)

2 Verifica-se um período seco, correspondente aos meses de Junho, Julho e Agosto, onde as precipitações não vão além dos 35 mm. Os restantes meses são húmidos, sendo de destacar o semestre de Outubro a Março onde se verificam as maiores precipitações médias mensais ao longo do ano (acima dos $100 \mathrm{~mm}$ ). 
para o desaparecimento ou estreitamento dos canais, e para alterações na profundidade e no assoreamento da laguna (AMORIM 2008).

No tocante às características geomorfológicas, a laguna de Aveiro está integrada numa longa faixa aplanada, com cotas normalmente inferiores a 200 metros, designada habitualmente na literatura geomorfológica por plataforma litoral. Em direcção ao interior, a plataforma é limitada pelo relevo marginal, designação adoptada por M.A. Araújo (1991). Tomando como ponto de referência o Rio Vouga, a Norte da laguna de Aveiro, este relevo apresenta um alinhamento contínuo segundo a orientação NNW/ /SSE. A Sul da laguna, o relevo marginal perde parte da sua rigidez tornando-se menos contínuo, devido aos vales talhados por vários cursos de água. Geologicamente, a laguna está localizada numa área de rochas sedimentares que se integram na Orla Meso-Cenozóica. Para o interior encontramos uma faixa de rochas muito antigas, de idade precâmbrica, integradas na ZOM (Zona Ossa-Morena). A leste dessa faixa as características geológicas mudam bastante e entra-se numa outra zona do maciço Hespérico, a ZCI (Zona Centro-Ibérica). Separando as duas zonas do Maciço Hespérico encontramos a faixa de cisalhamento Porto-Tomar (GoMes 2008).

Os terrenos da área envolvente da laguna são Cenozóicos, integrando um conjunto de conglomerados e areias datadas do Pliocénico / Plistocénico Inferior, junto às cidades de Murtosa, Aveiro e Ílhavo, e aluviões e areias de duna do Plistocénico médio e superior/Holocénico que cobrem a maior parte da área lagunar. As aluviões quaternárias são acumulações sedimentares de grande espessura compostas, sobretudo, por materiais arenosos, argilosos e siltíticos, bastante finos (ARAÚJO 1986; GOMES 2008). As areias de praia actuais bordejam o contacto da laguna com o mar. A presença destes materiais é justificada pelas variações glacio-eustáticas quaternárias que geraram uma enorme acumulação de aluviões transportadas pelos rios, bem como a presença de areias transportadas pelo vento e pela deriva litoral. Assim, a laguna de Aveiro é uma área de deposição flúvio-marinha que compõe um corpo hidrográfico complexo. De águas pouco profundas e de topografia intrincada, dado o número de ilhas interiores móveis e as extensas áreas intermareais (ABRANTES 2005), os canais lagunares apresentam uma configuração irregular, ora rectilíneos (quando criados artificialmente) ora meandrizados e de dimensões muito variáveis. São quatro os canais principais des- te sistema: S. Jacinto, Mira, Espinheiro e Ílhavo; e em igual número os afluentes principais: Rio Caster, Rio Antuã, Rio Vouga e Rio Boco, sendo o Vouga e o Antuã os de maior caudal. Para além do fluxo advindo do débito fluvial dos afluentes, e de acordo com I. Abrantes (2005), a hidrodinâmica da laguna é dominada por dois factores fundamentais:

- as marés: de carácter semi-diurno com uma amplitude média de $2 \mathrm{~m}$ na embocadura da barra, oscilando entre os $0,5 \mathrm{~m}$ nas marés mortas e $3,5 \mathrm{~m}^{3}$ nas marés vivas e cujas correntes são afectadas pela batimetria e morfologia dos canais da laguna.

- os ventos: que devido à sua forte intensidade e persistência (quer na direcção, quer na duração) alteram as correntes litorais;

Efectivamente não podemos esquecer o papel da deriva litoral em todo este sistema. Esta é provocada pela incidência da onda obliquamente à costa, originando correntes longitudinais, geralmente no sentido Norte-Sul que transportam os sedimentos.

Quanto maior for a energia das ondas e o seu ângulo de incidência, maior será a deriva litoral, desde que existam sedimentos disponíveis. No caso da laguna de Aveiro, a longa costa de carácter rectilíneo e a elevada energia das ondas, tornam a deriva potencial ${ }^{4}$ muito elevada, sendo este um dos factores determinantes na evolução e comportamento da frente costeira da laguna.

\subsection{Constituição e abertura da barra}

A sua constituição e evolução são geologicamente recentes. Segundo os trabalhos de S. Silva (1860, $1873,1875)$ que constituíram o ponto de partida para os de A. Loureiro (1904), F. Neves (1935, 1956), F. Martins (1946), A.A. Girão (1951), R. Cunha (1959), C. Abecassis (1961), S. Teixeira (1994) ou J.M.A. Dias et al. (1994) a laguna terá iniciado a sua formação há cerca de 1000 anos com o desenvolvimento de um cordão arenoso apoiado nas proximidades de Espinho. Desde o século X que existem documentos referentes à produção de sal em Aveiro. Ora “ $A$ laboração do sal só é possível em ambientes sedimentares confinados a regimes mareais, estuarinos ou lagunares. As referências históricas a salinas implicam, portanto, a existência coeva de qualquer barreira entre o mar e o local de laboração (...)" (TeIXEIRA 1994: 216). Contudo, a formação da restinga seria ainda muito confinada ao sector norte, junto à Torreira, visto que doações e descri-

\footnotetext{
3 Valores segundo a tabela anual de maré para Aveiro, marégrafo da barra, ano 2011. Dados disponibilizados pela Faculdade de Ciências da Universidade de Lisboa (http://webpages.fc.ul.pt/ cmantunes/hidrografia/hidro mares.html).

4 Quantidade de sedimentos que as ondas incidentes e as correntes por elas originadas podem transportar ao longo do ano.
} 
ções contemporâneas referem que os rios Vouga e Antuã desaguavam livremente no oceano e não havia qualquer restinga a ocidente da zona costeira da Murtosa. No entanto, a história da laguna e, sobretudo da sua abertura, é um percurso cheio de vicissitudes (Quadro I).

Segundo J.M.A. Dias (2004), nos séculos XIV e XV, as actuais lagoas de Óbidos ou de Santo André eram reentrâncias abertas ao mar e a laguna de Aveiro estava, também, bastante exposta ao mar. Contudo, apresentava já evidências da formação de um cordão litoral, bem desenvolvido no sentido Norte-Sul até às proximidades da ilha da Testada, com algumas ilhas de areia no seu interior. De acordo com F. Rebelo (2007) esta situação explica-se por uma intensa sedimentação provocada por cheias rápidas.

No início do século XVI, a abertura da laguna atingiu uma localização muito próxima da actual barra artificial, o que correspondeu a um momento de boa navegabilidade ${ }^{5}$ e de produção de $\mathrm{sal}^{6}$.

Desde muito cedo (século X) esta abertura mostrou tendência para deslocar-se para Sul. O crescimento da restinga ao longo do século XVII provoca a contínua migração da barra para Sul, encontrando-se já, em 1687, nos areais da Vagueira. No século XVIII, em 1756, a barra estava quase totalmente fechada junto ao areal de Mira (Fig. 2).

Quadro I. Evolução da laguna de Aveiro - fase pré-antrópica: posições naturais da barra e características da barra e da laguna. Síntese de várias fontes monográficas e cartográficas.

Table I. Evolution of the Aveiro lagoon - pre-anthropic phase: natural locations of the lagoon entrance and lagoon and entrance characteristics. Synthesis of several monographic and cartographic documents.

\begin{tabular}{|c|c|c|}
\hline Data & Localização Natural da Barra & Características da Laguna e da Barra \\
\hline 959 & $\begin{array}{l}\text { Aberta ao mar. Existência de uma restinga até à latitude } \\
\text { de Ovar. }\end{array}$ & $\begin{array}{l}\text { Existência de actividade salineira na área de Aveiro o que } \\
\text { indicia a presença de uma formação lagunar. }\end{array}$ \\
\hline 1407 & Barra natural localizada em frente à ilha da Testada. & $\begin{array}{l}\text { Formação de várias ilhas interiores na laguna; O rio Vouga } \\
\text { segue naturalmente em direcção à Murtosa. }\end{array}$ \\
\hline 1515 & Barra natural localizada em frente à ilha do Monte Farinha. & \\
\hline 1537 & Barra natural localizada no Muranzel. & Definição do canal de Ovar. \\
\hline 1687 & Barra natural localizada 3 léguas a sul de Aveiro. & $\begin{array}{l}\text { Engenheiros holandeses requisitados observam a barra por } 14 \\
\text { meses e confirmam o seu mau estado. }\end{array}$ \\
\hline 1756 & Barra natural localizada em Mira & \multirow{3}{*}{$\begin{array}{l}\text { Mau estado da barra e difíceis condições de navegabilidade } \\
\text { no interior da laguna. Problemas de salubridade e na produção } \\
\text { de sal. }\end{array}$} \\
\hline 1757 & $\begin{array}{l}\text { Barra natural localizada em Mira estando completamente } \\
\text { obstruída. Abertura de uma vala no areal por João de } \\
\text { Sousa Ribeiro. }\end{array}$ & \\
\hline 1758 & $\begin{array}{l}\text { Barra natural localizada junto ao areal da Vagueira, a 3/4 de } \\
\text { légua a sul da barra aberta no ano anterior. }\end{array}$ & \\
\hline $\begin{array}{c}1777 \text { a } \\
1780\end{array}$ & $\begin{array}{l}\text { Barra natural localizada na Vagueira, 3/4 de légua a sul da } \\
\text { barra aberta em } 1757 \text {. }\end{array}$ & $\begin{array}{l}\text { Grandes dificuldades de navegação no interior da laguna, } \\
\text { sobretudo no Verão. Alterações nas marés interiores da laguna } \\
\text { existindo grandes desfasamentos entre os canais e entre as } \\
\text { marés verificadas fora da laguna. }\end{array}$ \\
\hline 1788 & $\begin{array}{l}\text { Barra natural localizada muito próximo de Mira, a } 5 \text { léguas } \\
\text { de Aveiro. }\end{array}$ & $\begin{array}{l}\text { Barra em muito mau estado, muito estreita e em quase } \\
\text { obstrução. Grandes dificuldades de navegação no interior. }\end{array}$ \\
\hline 1791 & Barra natural localizada em Mira. & $\begin{array}{l}\text { Quase completamente obstruída tendo-se, momentaneamente, } \\
\text { aberto um regueirão em São Jacinto. Grandes dificuldades de } \\
\text { navegação no interior. Problemas de insalubridade. }\end{array}$ \\
\hline 1802 & Barra natural localizada em Mira. & $\begin{array}{l}\text { Barra natural completamente obstruída. Não há renovação } \\
\text { das águas salgadas. Marés e correntes interiores quase nulas. } \\
\text { Inundação das áreas junto aos canais. O porto de Aveiro está } \\
\text { obstruído. }\end{array}$ \\
\hline 1808 & $\begin{array}{l}\text { Abertura da barra artificial junto ao Forte Novo de Nossa } \\
\text { Senhora das Areias, localização que ainda mantém. }\end{array}$ & $\begin{array}{l}\text { Boas condições de navegabilidade no interior da laguna. } \\
\text { Facilidade na entrada das marés. }\end{array}$ \\
\hline
\end{tabular}

5 "No ano de 1552, o recenseamento geral da costa portuguesa refere 70 navios em Aveiro, não só o maior número de navios no Entre Minho e Vouga como a maior tonelagem total (5100) (...)" (AMORIM 2008: 38).

6 "Até ao século XVI (...) a equilibrada admissão da maré, espraiada em canais profundos, permitia fácil comunicação entre todas as urbes ribeirinhas, favorecia a produção de sal e oferecia, nos meandros das cales, grande riqueza de recursos naturais" (TEIXEIRA 1994: 225). 


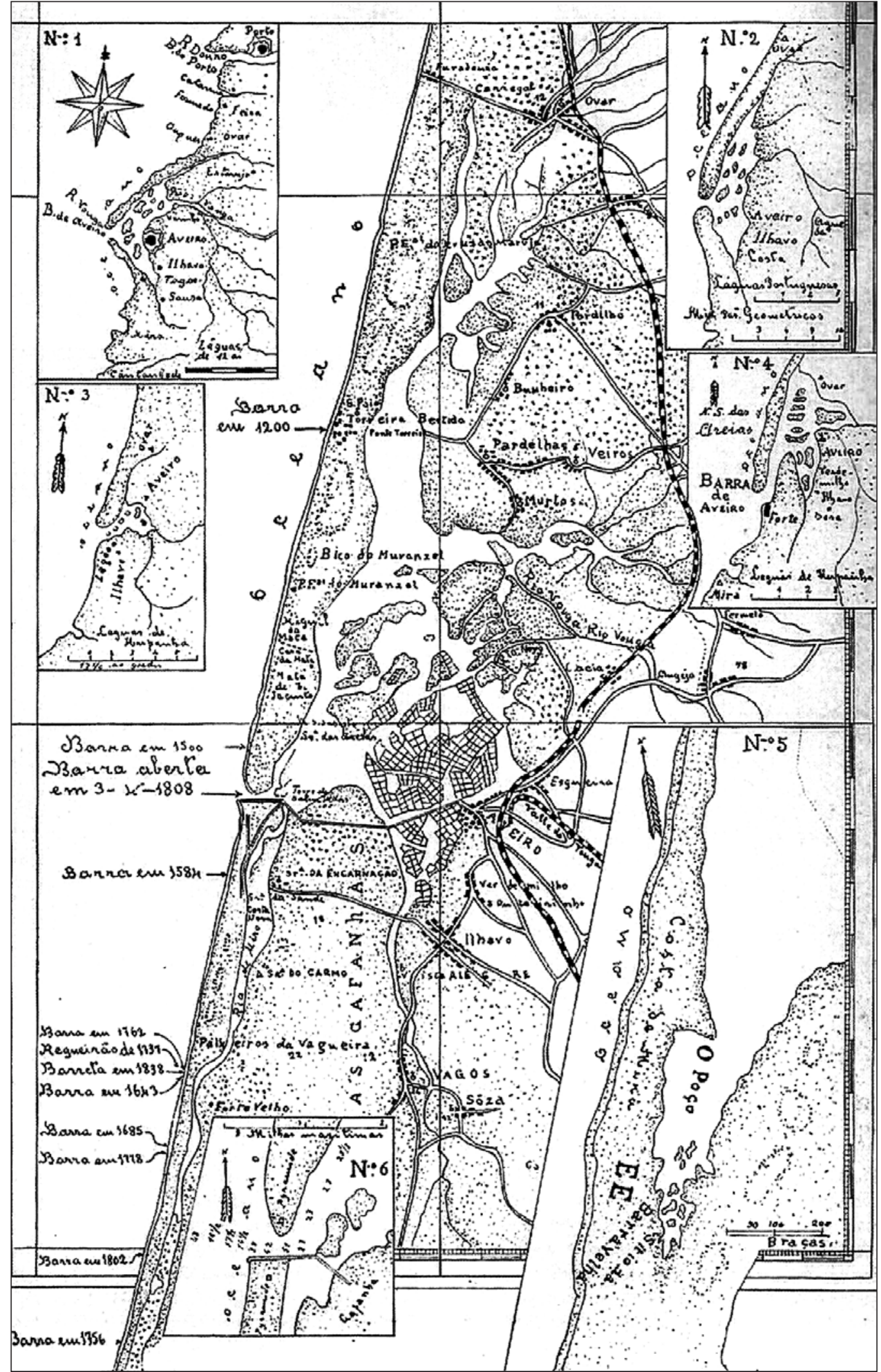

Fig. 2. Planta onde estão localizadas as diversas posições da barra de Aveiro ao longo do tempo, pelo engenheiro adjunto D. A. Mateus de Lima (seg. AMORIM 2008).

Fig. 2. Plan where are located the different positions of the harbour entrance in Aveiro over time, by the assistant engineer A. Mateus de Lima (after AMORIM 2008). 


\subsubsection{A abertura da barra}

Em 1757 deu-se a primeira intervenção com o intuito de desobstruir a entrada da laguna, cujas condições de navegabilidade eram mínimas. A barra continuava a deslocar-se para Sul, seguindo a deriva litoral predominante, e abria e fechava em diferentes pontos ao sabor das tempestades.

Vários projectos para a abertura e fixação da barra, foram apresentados mas nunca concretizados. O processo de assoreamento da laguna prossegue e, no início do século XIX, a abertura ao mar, entre a Vagueira e Mira, estava praticamente fechada. As condições de salubridade eram deploráveis e as consequências económicas graves, urgindo a reabertura ao mar (LOUREIRO 1904). Assim, a 3 de Abril de 1808, o engenheiro Luís Gomes de Carvalho põe em marcha o seu projecto, traçado 6 anos antes, e cria a abertura artificial da laguna de Aveiro na localização que até hoje se mantém.

\subsubsection{A fixação da barra e a navegabilidade}

Depois de uma espera de mais de cinquenta anos cheia de impasses, encontra-se na direcção das obras o artífice da sua abertura - Luís Gomes de Carvalho - e aí se mantém até 1824 . Durante este período, a barra e a laguna mantêm boas condições de navegabilidade que, no final deste período, começam a declinar devido ao assoreamento (Quadro II).
Nos dez anos que se seguiram, " $a$ administração do Estado, anarchisada pelas lutas civis, desinteressara-se (...)" (CUNHA 1923: 16) do problema da barra. A superintendência das obras não designou nenhum director, ficando estas a cargo dos operários mais conscientes que faziam reparações urgentes e imperiosas mantendo as condições mínimas de navegabilidade (SILVA 1875).

Após 1834, a direcção das obras da barra é entregue a sucessivos directores que, na curta duração do seu período de chefia, pouco ou nada fazem para melhorar o seu estado.

Em 1858, toma posse na administração da barra a mais longa direcção de sempre (28 anos de duração) chefiada pelo engenheiro Silvério Augusto Pereira da Silva. Homem de terreno, estuda a dinâmica da laguna e compreende a necessidade do seu conhecimento profundo para a obtenção de obras frutíferas. É a ele que devemos grande parte das fontes utilizadas neste trabalho já que, na sequência dos seus estudos e projectos de obras, organizou levantamentos cartográficos, ordenou estudos hidrográficos ${ }^{7}$, elaborou relatórios de obra detalhados e observou as correntes e marés. Em suma, esboçou a hidrodinâmica da laguna.

Durante toda a sua administração, e embora se sentisse limitado pelos condicionalismos financeiros impostos pelo governo, as várias obras que efectuou permitiram de novo a navegabilidade da barra e da laguna. Apesar disso, a sua direcção foi finalizada

Quadro II. Evolução da laguna de Aveiro - Fase antrópica: características da laguna e da barra após a fixação em 1808. Síntese de várias fontes monográficas e cartográficas.

Table II. Evolution of the Aveiro lagoon - anthropic phase: lagoon and lagoon entrance characteristics after setting the artificially entrance in 1808. Synthesis of several monographic and cartographic documents.

\begin{tabular}{|c|l|}
\hline Data & Características da Laguna e da Barra \\
\hline 1818 & Instabilidade da barra; construção de um novo molhe na margem norte; erosão na margem ocidental do canal de S. Jacinto. \\
\hline 1820 & Barra em más condições; diminuição da profundidade no canal principal e deterioração do dique. \\
\hline 1837 & Abertura de uma "barreta" 1 légua a sul da barra artificial. \\
\hline 1843 & $\begin{array}{l}\text { Barra em condições de obstrução. Acumulações sedimentares na entrada da barra e no seu interior. Formação de uma restinga } \\
\text { ancorada no dique Sul. Erosão na margem ocidental do canal de S. Jacinto e acumulação a Este (Fig. 3). }\end{array}$ \\
\hline 1849 & $\begin{array}{l}\text { Barra em condições de enorme obstrução. Dificuldades na admissão das marés, profundidades semelhantes às verificadas no } \\
\text { final do século XVIII; difícil navegação. }\end{array}$ \\
\hline $1859 *$ & $\begin{array}{l}\text { Condições semelhantes às verificadas desde 1843; aumento da dimensão da restinga ancorada no dique Sul (Fig. 4); dificul- } \\
\text { dades na entrada das marés; amplitude de marés de "águas-vivas" inferior a 1m; risco de inundações em toda a laguna. }\end{array}$ \\
\hline 1860 & $\begin{array}{l}\text { Barra artificial aberta e em funcionamento: desaparecimento da restinga Sul; maior facilidade da entrada das marés, } \\
\text { amplitudes de maré superior a 1m, aumento da profundidade no canal principal. }\end{array}$ \\
\hline 1873 & Obstrução da barra. Condições semelhantes às verificadas em 1859. \\
\hline 1874 & Reabertura da barra. Surgimento de uma restinga ancorada no dique Norte, com sentido N/S, em frente à barra artificial (Fig. 5). \\
\hline
\end{tabular}

* Administração de Silvério Augusto Pereira da Silva.

7 Os estudos foram efectuados pelo engenheiro hidrógrafo A.M. dos Reys. 
abruptamente com a dissolução da Junta Administrativa e Fiscal das Obras da Barra de Aveiro, em 1886, e sua substituição pela Circunscrição Hidráulica de Coimbra.

Durante o século XX, a barra e a laguna continuam a ser objecto de preocupação, já que a sua navegabilidade estava muito dependente das condições meteorológicas e da agitação do mar. Um novo conjunto de construções inicia-se em 1930, de que se destacam o sistema triangular de diques, projectados pelo engenheiro Von Hafe, e o prolongamento dos molhes Norte e Sul, que só terminam em 1987. Desde essa data, a laguna e a sua abertura assumiram uma configuração próxima da actual.

\subsection{Comportamento e evolução no período 1823 a 1886}

Sendo o nosso objectivo de estudo a evolução da laguna e o seu comportamento perante as construções efectuadas entre 1823 e 1886 , efectuaremos agora uma hipótese interpretativa sobre a sua dinâmica, com base na metodologia adoptada.

A figura 3 corresponde a uma cópia de um esboço da planta da barra em Agosto de 1843, realizada pelo engenheiro Silvério Augusto Pereira da Silva, com base no levantamento executado pelo engenheiro director, à época, João Luís Lopes. Nela podemos observar a configuração da embocadura artificial da laguna após a abertura realizada por Luís Gomes de Carvalho.

A sua obra consistiu num dique ${ }^{8}$ apoiado nos areais da Gafanha, que cortava o canal de Mira ${ }^{9}$, e se estendia pelos areais da Vagueira. Este dique cortou o cordão de areia que fechava a comunicação da laguna com o mar e dividiu-o, pela primeira vez, em dois sectores que começaram a comportar-se de maneira muito distinta. Foi intenção do engenheiro Luís Gomes de Carvalho cortar a comunicação do canal de Mira com a laguna (letras CM), uma vez que, diminuindo as correntes de maré na área meridional evitava possíveis reaberturas no cordão litoral a Sul da nova barra. A acontecer, esta abertura diminuiria a corrente do fluxo de maré e prejudicaria a manutenção da nova abertura. Contudo, e no sentido de manter a navegabilidade e a salubridade no canal de Mira, foi colocada uma comporta no dique (a "Cambeia") para que as águas fossem renovadas e passassem as embarcações.
Apesar da funcionalidade da barra durante 16 anos, a ausência de obras de manutenção, a deterioração do dique, a obstrução das comportas e o rompimento de uma nova abertura da laguna nos areais da Vagueira, entre 1838 e 1839, resultaram na degradação da barra nova e consequente assoreamento da laguna, bem patentes na Figura 3.

Se atentarmos na planta, há uma mudança de direcção da barra, agora virada a $\mathrm{WNW}$, e na forma do areal de S. Jacinto.

A Norte da barra, o sector do cordão litoral que apresentava uma grande saliência (Fig. 3, letra A), cresceu no sentido Norte-Sul cerca de 870 m, apoiado nos "reguladores"10, e chegou muito próximo do dique de abertura (Fig. 3, letra B).

O sector litoral a Sul exibia, igualmente, o crescimento de uma restinga arenosa no sentido Sul-Norte, com cerca de $550 \mathrm{~m}$ (letra $\mathrm{C}$ ), que ameaçava fechar a barra. Este crescimento deve-se, muito provavelmente, à falta de força das correntes de vazante que, por sua vez, foi provocada pela construção do dique junto ao canal de Mira (letras CM na Figura 3). Esta construção, apesar de contar com uma comporta que acabou por ficar obstruída, bloqueou o contributo do canal de Mira para a corrente de vazante, o que diminuiu fortemente o caudal de saída na barra fomentando a acumulação. Essa colmatação é evidente também nos bancos de areia, possivelmente submersos, figurados a tracejado, na entrada da barra (letra D).

Para além disso, o número de ilhas interiores da laguna aumentou consideravelmente, sobretudo no interior do ramo lagunar de Mira. O aumento da dimensão destes corpos arenosos é também visível, o que parece comprovar o aumento da sedimentação e a diminuição da profundidade da laguna.

A amplitude e o regime das marés foram afectados pelo estreitamento da entrada da laguna: a amplitude das marés e a sua penetração tornaram-se cada vez menores, pelo que o escoamento das águas do interior da laguna se terá processado muito lentamente. A acumulação de areias na entrada da laguna, diminuindo a força das correntes de maré, terá contribuído para a aproximação entre o nível de maré no interior da laguna e na sua abertura, o que terá provocado a diminuição da entrada de água na laguna durante a preia-mar, e uma menor corrente de descarga durante a baixa-mar (RIBEIRO et al. 1999, MARTINS 1946). Esta situação, por sua

\footnotetext{
8 Projectado é referenciado como molhe (estrutura costeira em que uma das extremidades se encontra em terra e outra no mar) mas, a construção efectuada por este engenheiro é, na verdade, um dique, uma vez que ambas as extremidades estão apoiadas em terra. 9 Posteriormente referenciado, também, como "canal da barra velha", referindo-se à barra localizada nos areais da Vagueira.

10 Construções de blocos de pedra colocadas aquando da abertura da barra, em 1808, para regularizar a corrente de vazante e evitar a erosão do cordão arenoso.
} 


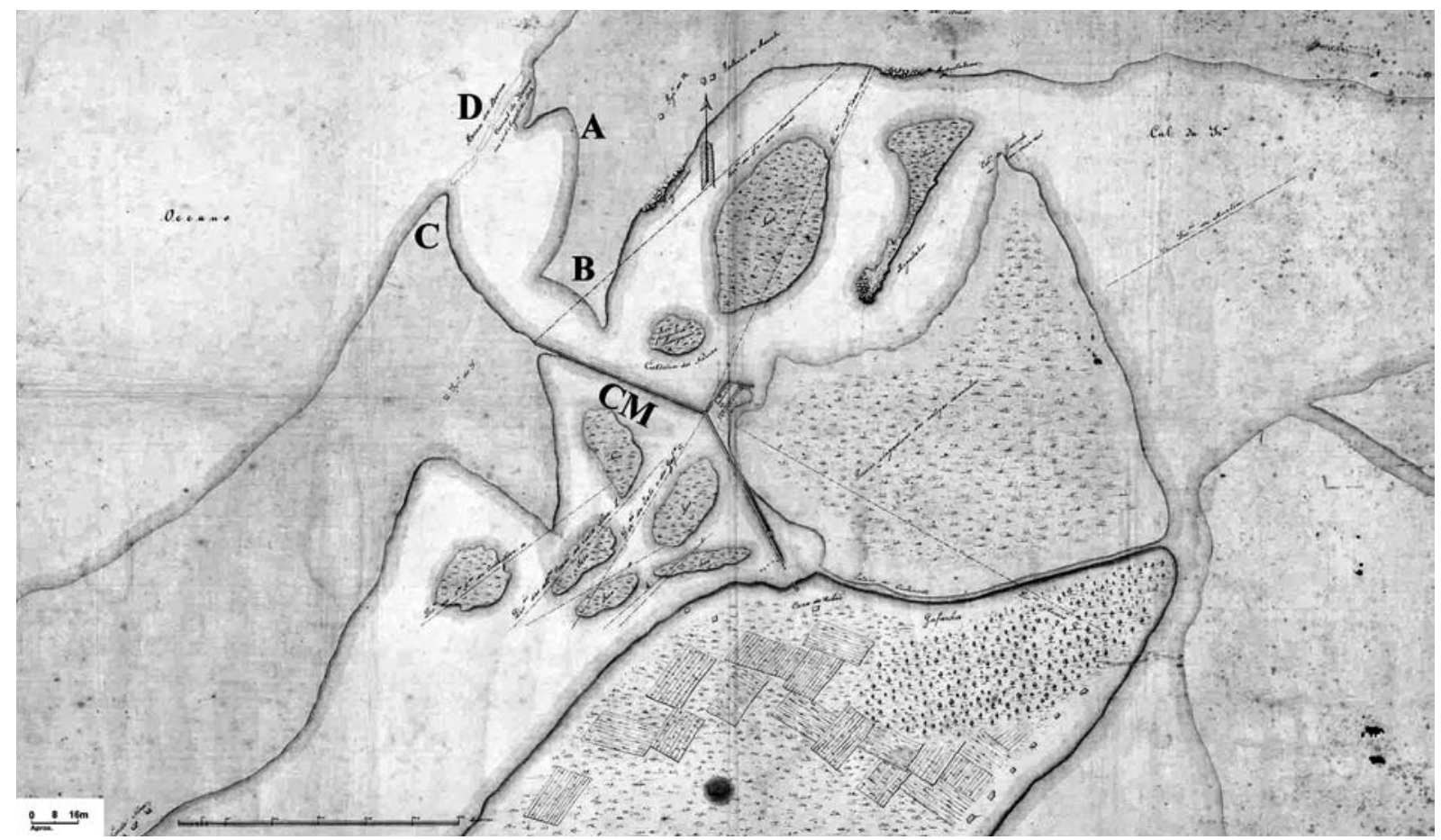

Fig. 3. Cópia de um Esboço da Planta da Barra de Aveiro, em Agosto de 1843, realizada pelo engenheiro Silvério Augusto Pereira da Silva, em 1876. Escala original [ca. 1: 8 000], 600 braças = [16,3 cm] (seg. AmORIM \& GARCIA 2008). Símbolos colocados pela autora.

Fig. 3. Copy of a sketch of the lagoon entrance in 1843 made by engineer Silvério Augusto Pereira da Silva, in 1876. Original scale [ca. 1: 8000], 600 fathoms $=[16.3 \mathrm{~cm}]$ (after AMORIM \& GARCIA 2008). Symbols of our own authorship.

vez, terá colaborado para a contínua acumulação de sedimentos visível no mapa.

Provavelmente, o corte efectuado pela abertura da barra no cordão de areias e a sua divisão em dois sectores, uma a Norte e outro a Sul da barra, veio interromper a deriva litoral o que poderá ter provocado uma maior erosão no sector Sul da restinga. Contudo, dada a escala do mapa em análise, tal não é possível comprovar.

Esta mobilidade e velocidade de sedimentação, patentes na representação cartográfica anterior, são corroboradas pelo mapa da Figura 4, realizado em 1859 pelo engenheiro Silvério da Silva.

Aqui podemos observar as diferentes configurações assumidas pela entrada da laguna numa escala mensal uma vez que estão representadas, por intermédio de cores distintas, as configurações do litoral nos meses de Junho, Agosto e Setembro (Fig. 4, letras J, A e S).

$\mathrm{O}$ menor assoreamento, em que o sector Norte surge mais recortado e a restinga a Sul quase desaparece, ocorre no mês de Setembro, fenómeno provavelmente, resultante das marés vivas equinociais, e que comprova o papel das marés como factor fundamental na hidrodinâmica da laguna. A maior amplitude destas marés vivas provoca um aumento do prisma de maré e uma vazante, mais intensa o que poderia desencadear maior erosão no sector Norte (DIAS 2009).

Este levantamento cartográfico integra-se no desenvolvimento das obras projectadas para a manutenção da barra de Aveiro. Repare-se que, perante o contínuo crescimento de uma restinga apoiada no sector Sul, Silvério da Silva planeia a extensão do dique Sul, para Oeste, de forma a impedir o crescimento da restinga de direç̧ão Sul-Norte que estava a dificultar a navegação. Da mesma forma, e com a intenção de rectificar o sector Norte dos areais de S. Jacinto, Silvério da Silva inicia a construção de um molhe norte, ainda provisório, em estacaria e faxinagem ${ }^{11}$.

Perante as obras efectuadas, nos primeiros 15 anos de administração, as condições da barra e da laguna eram favoráveis à navegabilidade mas, após

11 Trata-se de um tipo de construção linear que se aplica na construção de molhes, diques, consolidação de margens, socalcos, etc. Consiste numa armação de feixes de ramos de árvores atados com arame, posteriormente enchida com material rígido (pedra e saibro). 


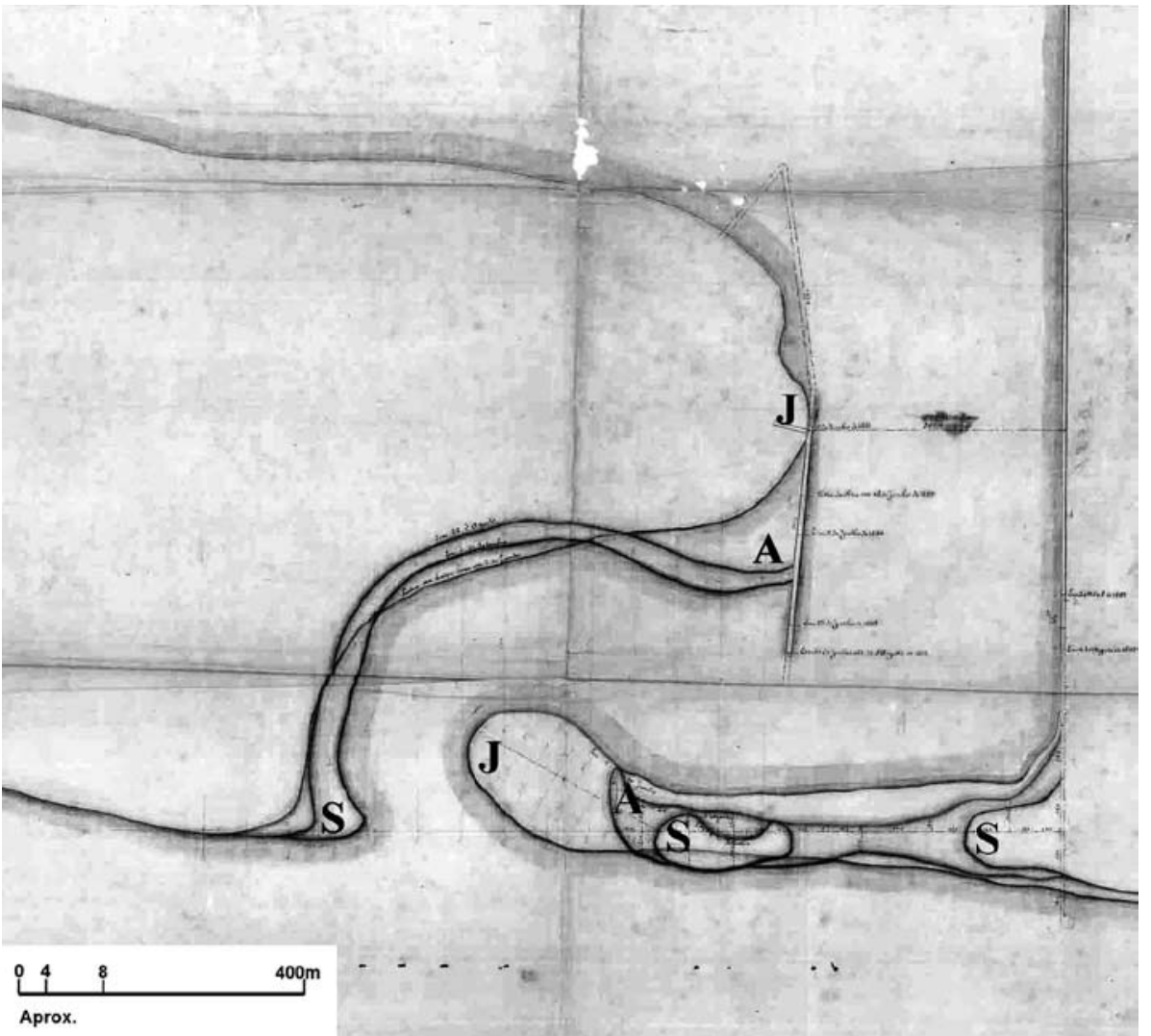

Fig. 4. Assoreamento da Barra d'Aveiro em 26 de Agosto de 1859 , Escala original 1: 4 000. Às letras J, A e $\mathrm{S}$ letra correspondem meses distintos: Junho (J), Agosto (A) e Setembro (S) (seg. APA, Cartografia, Pasta n. ${ }^{\circ} 1-$ n. $\left.^{\circ} 6\right)$. Símbolos colocados pela autora.

Fig. 4. Plan showing the silting of the lagoon entrance in June (J), August (A) and September (S) 1859 , Original scale 1: 4000 (after APA, Cartografia, Pasta $\left.n .^{\circ} 1-n .^{\circ} 6\right)$. Symbols of our own authorship. um prolongado estio em 1873, a barra adquiriu condições semelhantes às de 1858 .

Como é visível na Figura 5, que corresponde à cópia de uma parte da planta levantada em 1874 para as obras de melhoramento do porto e da barra de Aveiro, é clara a formação de uma restinga de sentido Norte-Sul, seguindo a direcção predominante da deriva litoral, com uma largura média de $150 \mathrm{~m}$.

No relatório onde a planta está inserida Silvério da Silva refere que, "Este cabedelo, seguindo no prosseguimento da costa, em frente ao canal da barra e à distância de 370 metros da extremidade ou testa do molhe, tem progredido muito neste sentido (...) cerca de 300 metros a contar do alinhamento do molhe" (SILVA 1875: 180).

As pequenas ilhas que surgiam, figuradas a tracejado no mapa anterior (Figura 3, letra D), foram integradas no cordão litoral que crescia e tapava a anterior abertura da barra.

Devido à estabilização e melhoramento do molhe Norte, a reentrância escavada na restinga desapareceu por completo (Figura 3, letra A).

Repare-se que a restinga apoiada no sector Sul da barra (que surgia nas Figuras 3 e 4 ) também já não é visível. Isto deve-se à reparação do dique e à criação de um novo sistema de comportas no canal de Mira as "Portas da Cambeia" (letras CM na Figura 3), que reabriu a circulação na área meridional da laguna. $\mathrm{O}$ maior volume de água disponível produziu um aumento das correntes na barra, sobretudo na vazante, que contribuíram para a sua limpeza e manutenção. Esta situação vem, mais uma vez, espelhar o carácter preponderante da deriva litoral na configuração da laguna. Para além de ter sido responsável pelo crescimento de uma restinga a Norte, o facto de a deriva litoral ter sido interrompida pelo molhe Norte, ainda diminuto, e o dique Sul, na embocadura da laguna, vem corroborar o comportamento distinto dos dois sectores litorais criados artificialmente, sendo este perceptível no mapa da Figura 5. Vejamos:

- a Norte da barra deu-se intensa acumulação de sedimentos devido ao efeito de retenção, resultando num balanço sedimentar global positivo. Assim, o sector norte surge com um extenso areal, largo e com corpos dunares;

- a Sul da barra, a deflecção da deriva litoral e a retenção de sedimentos a norte originaram um fornecimento sedimentar escasso, que resulta num balanço sedimentar negativo e numa diminuição do areal do sector Sul, mais estreito.

Em 1874, com base nos estudos hidrográficos efectuados a seu pedido e na observação, durante vários anos, da dinâmica da laguna, Silvério da Silva compreendeu que este espaço necessitava de novas 


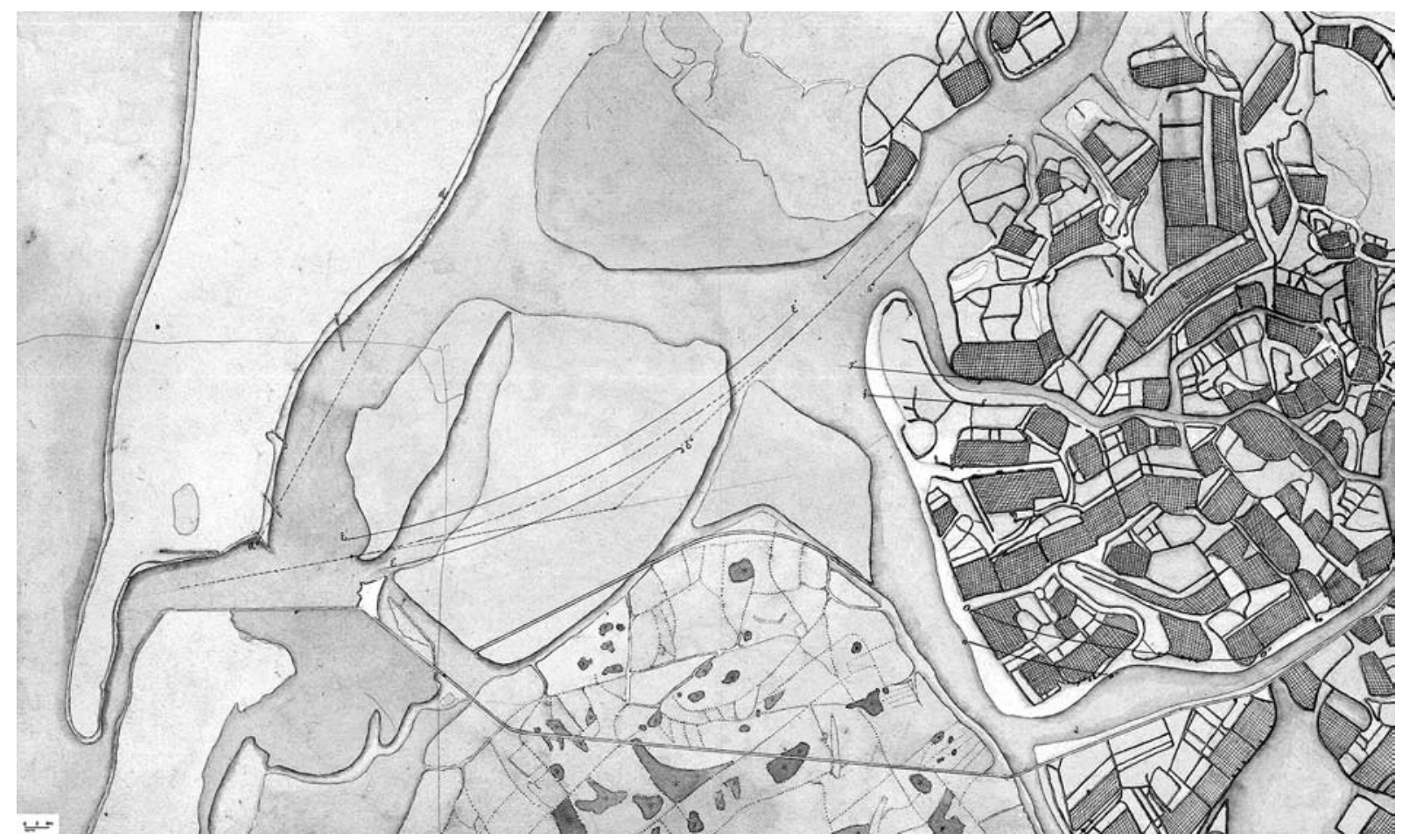

Fig. 5. Cópia de uma parte da Planta indicativa do Plano d' Obras para o melhoramento da Barra de Aveiro: Projecto de 26 de Fevereiro de 1874. Escala original [ca. 1: 20 000], $200 \mathrm{~m}=[10 \mathrm{~cm}$ ] (seg. AMORIM \& GARCIA 2008).

Fig. 5. Copy of part the plan drawn for the draft improvement the lagoon entrance, February 1874. Original scale [ca.1: 20 000] $200=$ $[10 \mathrm{~cm}]$. (after AMORIM \& GARCIA 2008).

intervenções, sobretudo que orientassem as correntes no sentido da barra. O esboço deste novo projecto pode ver-se na Figura 5, figurado com traçado fino. Este engenheiro propõe a abertura de um novo canal artificial, o canal do Espinheiro, que se prolongue até ao canal de abertura da laguna. Desta forma, consolidaria e aproveitaria o ramo lagunar de Mira e aumentaria as correntes de vazante, mantendo a posição da barra e aumentando a sua profundidade.

\section{CONClusões}

Assim, e em conclusão, face à curta análise efectuada às fontes cartográficas e monográficas produzidas, poderemos inferir que:

- as intervenções antrópicas efectuadas tiveram uma influência determinante na progressão do cordão de areia, na profundidade dos canais e na manutenção da barra;

- é evidente a tendência natural para a colmatação da laguna, sobretudo quando as correntes de maré se tornam mais fracas devido ao estreitamento da barra;

- a restinga avançou com uma notável velocidade (aproximadamente 88 metros por ano), entre 1584 e 1757.
Desta forma, parece-nos que ficou demonstrado que o método utilizado, com base na análise de documentos históricos, forneceu dados relevantes para a compreender o comportamento da laguna de Aveiro, pelo que a sua aplicabilidade a outros corpos lagunares semelhantes é exequível e recomendável. Abre-se, assim, um novo caminho para a Geomorfologia, apoiado na Historiografia, de onde poderão resultar novos conhecimentos e novas interpretações.

\section{BIBLIOGRAFIA}

\section{Manuscritos}

Livro da Despesa e dos Trabalhos das Obras da Barra de Aveiro: desde o $1 .^{\circ}$ de Novembro de 1875 até 30 de Junho de 1876. Aveiro: Junta Administrativa e Fiscal das Obras (Contem diversos desenhos e apontamentos).

Livro da Despesa e dos Trabalhos das Obras da Barra de Aveiro: ano económico 1876-1877. Aveiro: Junta Administrativa e Fiscal das Obras.

\section{Fontes Impressas}

ABECASSIS, C.K. 1961. As formações lagunares e seus problemas de engenharia do litoral (contribuição de um estudo sistemático). Lisboa: Junta de Investigação do Ultramar. 
ABRANTES, I.; DiAS; J.M. \& RochA, F. 2005. Matéria particulada em suspensão na Ria de Aveiro - variabilidade espacial e temporal e fluxos na embocadura. Iberian Coastal Holocene Paleoenvironmental Evolution - Coastal Hope 2005: Lisboa: Faculdade de Ciências da Universidade de Lisboa: 3-4.

Amorim, I. 2008. O Porto de Aveiro: entre a Terra e o Mar. Administração do Porto de Aveiro. Aveiro: APA.

Amorim, I. \& GARCiA, J. 2008. A Barra e os Portos da Ria de Aveiro 1808-1932. Arquivo da Administração do Porto de Aveiro. Catálogo da Exposição. Aveiro: APA.

ARAúJo. M.A. 1991. Evolução geomorfológica da plataforma litoral da região do Porto. Porto: Faculdade de Letras da Universidade do Porto (Tese de Doutoramento).

ARAúJO, M.A. 1986. Depósitos eólicos e lagunares fósseis na região de Esmoriz. Revista da Faculdade de Letras da Universidade do Porto - Geografia 2. 1. a Série: 53-63

BATEIRA, C.; GARCIA, J.C.; SoARES, L. 1998. O ‘terramoto’ de S. João (Melgaço) em 1841: Um percurso pela geomorfologia histórica. Actas do III Congresso da Apg, 1998. Porto: Faculdade de Letras da Universidade do Porto: 83-98.

Bettencourt, A. \& Ramos, L. (eds.) 2003. Estuários Portugueses. Lisboa: Instituto da Água Direcção dos Serviços do Planeamento.

BRITO, R.S. 1997. Portugal - Perfil Geográfico. Lisboa: Estampa.

Collins, B. 2005. Historical geomorfology and ecology of the Dungeness River delta and nearshore environments from the Dungeness Spit to Washington Harbour. Washington: University of Washington Libraries.

CunhA. R. 1959. O Porto de Aveiro, Conferencia realizada em 5 de Maio de 1923 na Sede da Associação dos Engenheiros Civis Portugueses. Aveiro: Tipografia "A Lusitânia".

DiAs, J.M. 2009. Hidro/morfologia da Ria de Aveiro: alterações de origem antropogénica e natural. Debater a Europa, Junho/Dezembro: 99-121.

DiAs, J.M.A. 2004. A história da evolução do litoral português nos últimos vinte milénios. A evolução geohistórica do litoral português e fenómenos correlativos. Lisboa: Universidade Aberta: 157-170.

Dias, J.M.A.; FerreirA, Ò.M.; PereirA, A.R. 1994. Estudo Sintético de Diagnóstico de Geomorfologia e da Dinâmica Sedimentar dos Troços Costeiros entre Espinho e Nazaré. ESAMIN - Estudos de Ambiente e Informática. Lisboa. Edição electrónica 2005: w3.ualg.pt/ jdias/JAD/eb_EspinhoNazare. html

DiAs, M.D. 1995. Os Mapas em Portugal - Da tradição aos novos rumos da Cartografia. Lisboa: Edições Cosmos.

Garcia, J.; MACIEIRINHA, J.; COSTA, N. 2008. A cartografia hidrográfica e as salinas de Aveiro. A Articulação do Sal Português aos circuitos mundiais: antigos e novos consumos. Porto: Instituto de História Moderna, Universidade do Porto: 265-272.

GIRÃO, A. DE AMORIM 1951. Evolução morfológica da Região do Baixo Vouga. Boletim do Centro de Estudos Geográficos 273: $75-85$

GOMES, A. 2008. Evolução geomorfológica da plataforma litoral entre Espinho e Águeda. Porto: Faculdade de Letras da Universidade do Porto (Tese de Doutoramento)

GRANJA, H. 2002. Reconstituição paleoambiental da zona costeira, a norte da laguna de Aveiro, desde a Idade Média até à actualidade. O litoral em Perspectiva Histórica (séc. XVI-
- XVIII). Instituto de História Moderna. Universidade do Porto. Porto: 93-109.

HELGREN, D.M. 1984. Historical Geomorphology and Geoarchaeology in the Southwestern Makgadikgadi Basin, Botswana. Annals of the Association of American Geographers 74 (2): 298-307.

Loureiro, A.A. 1904. Os Portos Maritimos de Portugal: Porto de Aveiro. Vol. 2. Lisboa: Imprensa Nacional.

MedeIros, C. 2005. Geografia de Portugal-O Ambiente Físico. Vol. 1. Lisboa: Círculo de Leitores.

MARTINS, F. 1946. A configuração do litoral português no último quartel do século XIV - apostila a um mapa. Biblos 22 (I): 163-197.

Neves, F. 1935. Breve História da Barra de Aveiro. Arquivo do Distrito de Aveiro. Volume 1: 219-234.

NeVES, F. 1956. Documentos Relativos à Abertura da Actual Barra de Aveiro. Arquivo do Distrito de Aveiro 22 (88): 275-281.

Pethick, J. 1984. An Introduction to Coastal Geomorphology. London: Edward Arnold.

PHILLIPS, J.D. 2006. Deterministic chaos and historical geomorphology: A review and look forward. Geomorphology 76 (1-2): 109-121.

REBELo, F. 2007. O risco de sedimentação na laguna de Aveiro: leitura actual de um texto de Amorim Girão (1922). Territorium 14: 63-69.

Ribeiro, A.; Antunes, M.T.; FERreira, M.P.; Rochas, R.B.; SOARES, A.F.; ZBYSZEWSKI, G.; MOITINHO DE AlMEIDA, F.; CARVAlHo, D. \& Monteiro, J.H. 1979. Introduction à la géologie générale du Portugal. Lisboa: Serviços Geológicos de Portugal.

Ribeiro, O.; Lautensach, H. \& Daveau, S. 1999. Geografia de Portugal - Posição Geográfica e Território. Vol. I. Lisboa: João Sá da Costa Editores.

Ribeiro, O.; Lautensach, H. \& Daveau, S. 1999. Geografia de Portugal-O Ritmo Climático e Paisagem. Vol. II. Lisboa: João Sá da Costa Editores.

Silva, S. 1860. Projecto do Melhoramento da Barra de Aveiro. Relatório do Boletim das Obras Públicas Comércio e Indústria. Janeiro a Julho. Lisboa: Ministério das Obras Públicas: 229-260.

SILVA, S. 1873. Notícia Acerca das Obras Públicas do Districto de Aveiro. Revista das Obras Públicas e Minas 4 (45): 325-364.

Silva, S. 1875. Barra de Aveiro. Revista das Obras Públicas e Minas 6 (64 a 66): 165-269.

TeIXEIRA, S.L. 1994. Dinâmica Morfosedimentar da Ria de Aveiro (Portugal). Lisboa: Universidade de Lisboa (Tese Doutoramento).

\section{Websites}

Faculdade De CiênCIAS DA Universidade DE Lisboa (2011). http://webpages.fc.ul.pt/ cmantunes/hidrografia/hidro_mares. html

GESTÃo CosteIRA InTEgRAdA (2011). Revista de Gestão Costeira Integrada (JICZM - Journal of Integrated Coastal Zone Management): http://www.aprh.pt/rgci/glossario/index.html

GLOBAL LAND COVER FACILITY (2011). http://glcf.umiacs.umd. edu/index.shtml 